\title{
Clinical and Research Implications of Gambling Disorder in DSM-5
}

\author{
Jeremiah Weinstock • Carla J. Rash
}

Published online: 13 June 2014

(C) Springer International Publishing AG 2014

\begin{abstract}
The fifth edition of the Diagnostic and Statistical Manual of Mental Disorders contains significant changes related to the diagnosis of gambling problems. These changes include the renaming of the disorder from pathological gambling to gambling disorder, reclassification of gambling disorder from an impulse control disorder to an addictive disorder, removal of the illegal acts criterion, lowering diagnostic threshold to endorsement of four criteria, and recognizing that the course of the disorder is no longer chronic for all diagnosed. This paper reviews the rationale and research support for these changes. Implications of the new revisions for both research and clinical practice are reviewed, including a discussion about future directions for research efforts.
\end{abstract}

Keywords Pathological gambling · Problem gambling · Addictive disorders · Behavioral addiction · DSM-5

\section{Introduction}

Problems arising from excessive gambling have long been recognized throughout the world. For example, the Mahabharata, an ancient Hindu epic poem that dates back to 800 or 900 B.C., includes a story about a prince who risks and loses everything during a game of dice. His losses include his kingdom, his own freedom, and his wife. However, it was not until 1980 with the introduction of pathological gambling

\footnotetext{
J. Weinstock $(\square)$

Department of Psychology, Saint Louis University, St. Louis, MO 63103, USA

e-mail: jweinsto@slu.edu

C. J. Rash

Calhoun Cardiovascular Center - Division of Behavioral Health, University of Connecticut Health Center, Farmington, CT 06030-3944, USA
}

that that gambling problems were officially recognized as a psychiatric disorder in the third edition of the Diagnostic and Statistical Manual of Mental Disorders (DSM) [1]. Today, approximately $1 \%$ of the world's population meets criteria for the disorder [2-4], and its consequences upon the individual, loved ones, and society are considerable. An additional 1-4\% of the population meets clinically significant but subdiagnostic levels of problem gambling [5-7, 4]. These subdiagnostic gamblers experience substantial negative repercussions from their gambling behavior. The goal of this review is to examine (1) how the latest revision to the DSM (i.e., DSM-5) [8] furthers our conceptualization of pathological gambling and (2) what impact these revisions have upon clinical practice and future research efforts. Throughout the remainder of this review, pathological gambling will be referred to as gambling disorder, its name in DSM-5.

\section{DSM-5 Changes}

The DSM is designed as a diagnostic tool for clinicians to aid in the recognition and treatment of psychiatric disorders. While updates and revisions are based upon empirical evidence, decisions about changes were made by votes from a committee of experts in the field and by decree from the DSM5 oversight committee [9]. Thus, it is a document that reflects our current social and political views and is a product of human interaction and compromise. Criticisms of the DSM abound stemming from the tension of (1) creating a reliable and observable set of diagnostic criteria and (2) the need to create diagnostic categories that reflect underlying causes. Both are important goals as the first ensures clinicians agree on a diagnosis and the second ensures that the diagnosis is accurate, valid, and that the appropriate treatment is then offered; however, our current knowledge about psychopathology, especially underlying causes, remains incomplete. Thus, 
the DSM-5 remains an imperfect document that represents humanity's best effort to categorize psychopathology.

The major revisions from the fourth edition of the DSM (i.e., DSM-IV-TR) to DSM-5 include (1) reclassification of pathological gambling from impulse control disorders to a newly created category labeled "Substance-Related and Addictive Disorders" that also includes substance use disorders; (2) renaming of pathological gambling to gambling disorder; (3) removal of the illegal acts criterion; and (4) lowering the diagnostic threshold for diagnosis from five to four criteria. The text describing gambling disorder were also revised and updated. Aside from the renaming of the disorder, which was done for nomenclature consistency within the category and to reduce stigma associated with the diagnostic label (i.e., removing "pathological"), the changes were based upon empirical evidence that is summarized and discussed below.

\section{Reclassification to Substance-Related and Addictive Disorders}

Within DSM-5, disorders were reorganized and grouped together to "reflect common underlying vulnerabilities for a larger group of disorders" [8] [p. xli]. Moving gambling disorder to the addictive disorders category was implemented based upon findings that the disorder is very similar to substance use disorders in terms of etiology, symptoms, course, correlates, and treatment approaches [10], although skepticism remains [9]. Beginning with genetic factors, significant overlap exists between alcohol use disorder and gambling disorder [11-14]. Family cohort studies find that gambling disorder runs in families and that families with gambling disorder frequently have histories of substance use disorder [15]. Findings from neuroscience on brain functioning, activation, and differences in comparison with healthy controls are strikingly similar between substance use disorders and gambling disorder (for a review see Noël et al. [16••] and Potenza [17]). Moreover, etiological models of gambling and alcohol use disorder are also strikingly similar, with a developmental pathway that accounts for a strong genetic contribution in the onset of the disorder (e.g., Type B, antisocialimpulsivist) and a developmental pathway that describes problems that arise later in life, typically in response to other stressors $[18,19 \bullet \cdot]$. Symptoms of substance use disorders and gambling disorder in DSM-5 have substantial overlap with the same five symptoms appearing in both diagnostic criteria sets (i.e., preoccupation, loss of control, psychosocial consequences in various contexts, tolerance, withdrawal) [20,21]. Finally, treatments for gambling disorder are frequently the same ones used to treat alcohol and other substance use disorders. Common approaches with empirical support include 12-step modalities, cognitive-behavioral therapy, motivational interviewing, and opiate antagonists (although no medications are currently approved in the USA by the Food and Drug Administration for gambling disorder) [22, 23••].

The benefits of gambling disorder being grouped within addictive disorders primarily center on increased awareness and attention on the comorbidity between disorders. Within individuals with gambling disorder, over $50 \%$ have a lifetime substance use disorder [7], and conversely rates of gambling disorder are elevated in individuals with substance use disorders compared with the general population [4]. Prevalence rates are even higher in treatment-seeking samples (e.g., Cowlishaw et al. [24] and Ibáñez et al. [25]). The importance of comorbidity lies in its impact on the individual and treatment. Individuals with comorbid alcohol and gambling disorder tend to have more severe problems [26-28]. In terms of treatment, a history of a comorbid substance use disorder often hampers efforts to achieve gambling abstinence, and a current alcohol use disorder increases the risk of relapse after gambling treatment [29]. Conversely, gambling disorder is frequently comorbid with substance use disorders but is infrequently diagnosed and treated in outpatient and/or inpatient substance use disorder treatment settings [24]. Increased attention in these settings is particularly important as the presence of a comorbid gambling disorder negatively impacts substance use disorders' treatment retention and outcome [30]. With inclusion in the addictive disorders category, screening for and treating gambling disorder will hopefully become part of routine clinical practice within these clinics.

Finally, the DSM-5 explicitly recognizes that comorbidity and current scientific evidence is blurring the lines between diagnostic categories. This recognition furthers the idea that transdiagnostic processes frequently underlie the development of several related disorders (e.g., multifinality) [31, 32••]. The move of gambling disorder to the addictive disorders category recognizes that gambling disorder and substance use disorders are frequently comorbid and share many of the same underlying etiological and sustaining factors, such as the previously highlighted genetic overlap, traumatic experiences, coping via dissociation, impulsivity, and negative reinforcement [33, $34 \bullet \bullet, 35]$. The blurring of lines between diagnostic categories has implications for treatment. Integrated treatments for comorbid conditions, such as post-traumatic stress disorder and gambling disorder, have been shown to be beneficial [36]. The same may hold true for integrated treatments for gambling and substance use disorders. Additionally, common transdiagnostic processes, such as impulsivity and anger, have been shown to be related to poor treatment adherence [37-39]. Integrated treatments focusing on these transdiagnostic processes can be beneficial (e.g., Korman et al. [40]) and provide opportunity for cost-efficient group treatments that are tailored to specific underlying issues that affect numerous individuals with a variety of disorders. Unfortunately, there is a dearth of evidence on integrated treatments targeting gambling disorder at this time to effectively guide clinicians. Other questions 
remain about what other transdiagnostic processes lead to and maintain addictive disorders and what factors determine which disorder develops or develops first. Fortunately, interest in transdiagnostic processes has grown exponentially recently, primarily as an alternative means for understanding psychopathology [41, 42]. Gambling disorder has much to contribute to these efforts, particularly since it does not involve consumption of a substance that alters brain chemistry. Investigations incorporating gambling disorder may therefore allow for parceling out of effects that are due to the underlying addictive process and effects that are due to chronic administration of a psychoactive substance.

\section{Removal of the Illegal Acts Criterion}

The elimination of the illegal acts criterion was due to relatively low rates of endorsement, stability of gambling disorder's prevalence without this item, and limited diagnostic utility. While worded slightly different, the legal problems criterion was also removed from substance use disorders' diagnostic set. Within gambling disorder, numerous studies found that the illegal acts criterion was consistently the least common DSM-IV symptom endorsed and is only typically endorsed by the most severe gamblers [43-45]. For example, in a large community sample of individuals endorsing at least one diagnostic criterion, the illegal acts criterion was endorsed by over $60 \%$ of individuals meeting eight to ten DSM-IV pathological gambling criteria; meanwhile only $0.4 \%$ of those meeting one to two criteria endorsed this item [46]. Removal of the illegal acts criterion also has minimal impact on the diagnostic status of individuals, with less than $3 \%$ of individuals diagnosed with gambling disorder under DSM-IV conceptualization losing their diagnosis with the elimination of this item prior to taking into account the newly lowered threshold in the DSM-5 criteria [47, 48]. Therefore, this criterion is better conceptualized as a marker of severity, rather than a necessary criterion for diagnosis. While the criterion was removed, the relationship to the disorder was not completely deleted from the text. Illegal acts remains in the section describing the diagnostic features [8, p. 585], but is now subsumed under lying to conceal the extent of gambling. Therefore, while it is no longer a separate diagnostic criterion of the disorder, it remains a vital part of gambling disorder's lexicon and a useful clinical tool for measuring severity and potential for involvement with the legal system.

\section{Diagnostic Threshold Lowered}

In DSM-5, the threshold for diagnosis was lowered from endorsement of five symptoms to four symptoms. Several studies supported this change as they found that meeting four criteria had the best diagnostic accuracy when treatment seeking was used as the criterion [49-51]. Unfortunately, treatment seeking is a complex act that may not be the best indicator or "gold standard" for gambling disorder. Approaches that employ multiple sources (e.g., afflicted individual, clinician, collateral) to evaluate the criterion may be a better indicator.

The most striking aspect of the diagnostic threshold is the discrepancy of impairment/dysfunction that is required for diagnosis and differences in how severity is quantified between gambling disorder and substance use disorders. As shown in Table 1, within substance use disorders an individual must endorse at least two of 11 diagnostic criteria [8], while within gambling disorder an individual must endorse a higher threshold to enable a diagnosis (i.e., at least four of nine criteria). Table 1 also displays the discrepant symptom counts associated with severity ratings. For example, an individual who endorses loss of control, preoccupation, and psychosocial consequences in relation to substance use would be diagnosed with a mild substance use disorder; meanwhile, someone who endorses these same three symptoms in relation to gambling would not receive a diagnosis. Additionally, an individual receiving a mild severity rating for gambling disorder would receive a moderate severity rating for endorsing the same number of symptoms. As discussed below, this inconsistency may be an area for future research to establish whether negative impact of a mild gambling disorder reaches a level of clinical significance comparable with the negative effects of a mild substance disorder.

Evidence to date suggests that sub-diagnostic gamblers do experience negative consequences related to their gambling behavior, including large amounts of gambling-related debt, suicidal ideation, and comorbid psychopathology [46, 47, 52]. The most commonly endorsed diagnostic symptoms by subdiagnostic gamblers are withdrawal, chasing losses, lying to others, and escape gambling, with lower endorsement rates for the more severe symptoms (e.g., jeopardizing relationships, illegal behavior, loss of control, financial bailouts) [45]. Moreover, a significant portion of sub-diagnostic gamblers acknowledge problems related to their gambling and present for treatment $[47,53,54]$. With these negative consequences in mind, strong consideration is warranted for lowering the diagnostic threshold of gambling disorder to be in line with other disorders in the category.

Lowering the diagnostic threshold such that it is equivalent with substance use disorders (i.e., endorsing two or more criteria) would be a significant departure from the prior DSM conceptualizations and is fraught with potential political complications. Forefront among these issues is that a lowered threshold would result in a large increase in prevalence rates. Some would argue that this change would be beneficial, especially in terms of prevention and the brief intervention that might reduce the risk of developing severe problems at a later date (e.g., Larimer et al. [55]). Others would argue that 
Table 1 Diagnostic and Statistical Manual of Mental Disorders, fifth edition (DSM-5) diagnostic threshold and severity ratings

\begin{tabular}{|c|c|c|}
\hline & Substance use disorder & Gambling disorder \\
\hline Threshold for diagnosis & 2 of 11 criteria & 4 of 9 symptoms \\
\hline \multicolumn{3}{|l|}{ Severity ratings } \\
\hline Mild & $2-3$ criteria met & 4-5 criteria met \\
\hline Moderate & 4-5 criteria met & 6-7 criteria met \\
\hline Severe & $\geq 6$ criteria met & $\geq 8$ criteria met \\
\hline
\end{tabular}

this change would overly pathologize normative human behavior. Another consideration is whether treatment is necessary for these mild cases or whether mild forms of the disorder largely resolve on their own, which may suggest that diagnosis of mild cases may be unnecessary. Studies that examine and directly compare the harm and lifetime course experienced by sub-threshold gamblers in relation to individuals with mild severity substance use disorders are needed to provide clarity regarding the validity of altering the diagnostic threshold. If findings demonstrate that currently defined subdiagnostic gamblers are experiencing the criterion for establishing diagnostic thresholds in DSM-5, which is "clinically significant distress or impairment in social, occupational, or other important areas of functioning" [8, p. 21] related to their gambling behavior, and that this distress is similar in nature/ severity to the harm experienced by individuals being diagnosed with a mild substance use disorder, then there may be sufficient evidence to lower the threshold. Andrews and colleagues [56] provide an exemplar for how to approach an investigation of this type.

The research community and treatment providers have already moved ahead of DSM-5 by examining and providing interventions for sub-diagnostic gamblers. Interventions typically offered include brief interventions such as motivational interviewing, brief versions of cognitive-behavioral therapy, and even pamphlets with suggestions on how to change gambling habits. These studies find that the brief interventions are well received, significantly reduce harm, and improve overall functioning (e.g., Larimer et al. [55] and Hodgins et al. [57]).

\section{Text Revisions}

The revisions of the text describing gambling disorder and its associated features are not to be ignored. The revisions contain important updates on our current scientific understanding of the disorder. Two revisions warrant attention: (1) gambling disorder is now recognized as a "behavioral addiction"; and (2) the disorder's course is no longer considered chronic and unremitting.
DSM-5 is the first diagnostic system to recognize behavioral addictions. These disorders lack the ingestion of a psychoactive substance that is the core of traditional conceptualizations of addiction. Yet, individuals with behavioral addictions will manifest other patterns consistent with substance use disorders. These shared elements include the commandeering of the natural reward pathway, development of tolerance and withdrawal, and engaging in the behavior despite harm experienced by the individual and others [58, 59]. Further similarities are found when comparing gambling disorder and substance disorders with regards to life course, treatment outcome, diagnostic criteria (with some differences), and the content of existing treatment protocols. Petry [60] and Potenza [61] provide reviews of the similarities and differences between pathological gambling and substance disorders. Gambling disorder was the first and only non-substance use disorder to be classified into the new substance-related and addictive disorders chapter. However, internet gaming disorder was listed under topics for further consideration given that it is better researched relative to other potential behavioral addictions such as exercise, sex, or shopping (American Psychiatric Association [8, p. 795; Petry et al. [62]).

As a behavioral addiction, gambling disorder has several criteria that are unique to the behavior, such as "chasing losses." In comparison, substance use disorders' criteria are identical across all ten substances. Whether gambling criteria items and/or threshold will be or should be shaped toward consistency with the substance disorder is a matter for future research and discussion and also raises the question of how similar in construct gambling disorder is to traditionally viewed addictions [9]. This discussion may lead in the direction of tailoring the substance and gambling disorder criteria toward similarity or, conversely, moving the behavioral addictions into their own category.

Another change within the text is the recognition that gambling disorder is not a persistent chronic disorder and that individuals can fluctuate between problematic and nonproblematic phases. It is a significant departure from prior conceptualizations of the disorder. However, the evidence is clear from prospective studies that gambling disorder can be episodic and transitory in nature [63]. Retrospective studies also find that one-third of individuals with lifetime gambling disorder no longer meet past-year criteria for the disorder, and these changes are not due to treatment as few sought professional help $[64,65]$. This is not to say that the disorder is not chronic for some individuals, but that for many it is not a lifelong persistent problem.

In terms of clinical practice, this conceptualization regarding the course of the disorder suggests a stepped-care or adaptive-care approach to treatment for gambling disorder is warranted. This approach begins by offering the least intensive dose of treatment with hopes of enacting change; 
however, through ongoing monitoring if the individual continues to experience harm/negative consequences, the intensity of treatment is increased in hopes of making gains. Steppedcare is viewed as cost effective as individuals are initially offered minimal treatment and the more expensive and intensive treatments are only provided if the minimal treatments prove ineffective. Moreover, this approach implicitly accepts that for some recovery is simply a product of motivation to change and a brief intervention is all that is warranted, while for others the presence and severity of the disorder will fluctuate over time and ongoing monitoring is warranted with treatment offered when the disorder reoccurs [66].

\section{Future Directions and Conclusion}

Looking to the future, the field of neuroscience has much to contribute to advancing our knowledge about gambling disorder. In particular, it can confirm much of what we already see clinically in our clients and provides explanations for these phenomena. For example, recent findings suggest that the insula region of the brain is activated when cognitive distortions and distress occur $[67,68 \bullet \cdot$. The insula is responsible for integrating sensations throughout our body (i.e., interoceptive awareness) and directing subsequent action based upon these feelings. Clinically, we know that when individuals with gambling disorder experience distress they make harmful choices (i.e., gambling) despite knowledge of the adverse outcomes that are likely to happen. These choices to gamble are often puzzling to others (e.g., "Why can't you just stop?!"); however, when viewed in the context that gambling relieves uncomfortable feelings, the choice becomes understandable. It also provides an explanation for why prevention and intervention efforts that teach probability have little effect [69], as cognitive distortions (e.g., "I feel lucky!") may more accurately be interpreted as feelings rather than thoughts. Moreover, these findings regarding the role of the insula suggest that mindfulness-based treatments warrant investigation as a treatment for gambling disorder, as these interventions seek to train individuals how to respond or not respond to distressing feelings [70]. Going beyond neuroscience, significant work is still needed on developing and refining treatments for gambling disorder and the underlying causes, as many who seek professional help either discontinue treatment prior to making gains or do not successfully enter into a period of stable remission.

Overall, the fifth edition of the DSM has made important revisions to the description and criteria set of the disorder formerly known as pathological gambling. The changes from the DSM-IV-TR to DSM-5 are meaningful and improve our diagnostic and prognostic capabilities. Gambling disorder is now categorized as an addiction and housed together with substance use disorders. While differences remain between the disorders, there is considerable overlap. The clinical benefits of being grouped in an addictions category center around optimism that gambling disorder will be increasingly recognized as an addiction that is worthy of screening for and treating in a variety of settings. For researchers, grouping gambling disorder with other addictions is beneficial as the disorder has much to offer in the pursuit of knowledge about addiction, and funding agencies may be more receptive to supporting gambling research as it is now clearly labeled an addictive disorder. In conclusion, we anticipate that our understanding regarding the etiology, diagnosis, maintenance factors, and treatment for gambling disorder will continue to improve, and such advances will yield significant improvements in patient care.

\section{Compliance with Ethics Guidelines}

Conflict of Interest Jeremiah Weinstock reports that he is a principal investigator on a grant funded by the National Center for Responsible Gaming.

Carla J. Rash declares no conflicts of interest.

Human and Animal Rights and Informed Consent This article does not contain any studies with human or animal subjects performed by any of the authors.

\section{References}

Papers of particular interest, published recently, have been highlighted as:

•- Of major importance

1. American Psychiatric Association. Diagnostic and Statistical Manual of Mental Disorders. 3rd ed. Washington, DC: American Psychiatric Association; 1980.

2. Devlin ME, Walton D. The prevalence of problem gambling in New Zealand as measured by the PGSI: adjusting prevalence estimates using meta-analysis. Int Gambl Stud. 2012;12(2):17797. doi:10.1080/14459795.2011.653384.

3. Sassen M, Kraus L, Buhringer G, Pabst A, Piontek D, Taqi Z. Gambling among adults in Germany: prevalence, disorder and risk factors. Sucht. 2011;57(4):249-57. doi:10.1024/0939-5911. a 000115 .

4. Petry NM, Stinson FS, Grant BF. Comorbidity of DSM-IV pathological gambling and other psychiatric disorders: results from the National Epidemiologic Survey on Alcohol and Related Conditions. J Clin Psychiatry. 2005;66(5):564-74. doi:10.4088/ JCP.v66n0504.

5. Shaffer HJ, Hall MN, Vander BJ. Estimating the prevalence of disordered gambling behavior in the United States and Canada: a research synthesis. Am J Public Health. 1999;89(9):1369-76. doi: 10.2105/ajph.89.9.1369.

6. Williams RJ, Lee CK, Back KJ. The prevalence and nature of gambling and problem gambling in South Korea. Soc Psychiatry Psychiatr Epidemiol. 2013;48(5):821-34. doi:10.1007/s00127012-0580-z.

7. Lorains FK, Cowlishaw S, Thomas SA. Prevalence of comorbid disorders in problem and pathological gambling: systematic review 
and meta-analysis of population surveys. Addiction. 2011;106(3): 490-8. doi:10.1111/j.1360-0443.2010.03300.x.

8. American Psychiatric Association. Diagnostic and statistical manual of mental disorders. 5th ed. Washington, DC: American Psychiatric Association; 2013.

9. Schuckit MA. Editor's corner: DSM-5 - Ready or not, here it comes. J Stud Alcohol Drugs. 2013;74(5):661-3.

10. Grant JE, Potenza MN, Weinstein A, Gorelick DA. Introduction to behavioral addictions. Am J Drug Alcohol Abuse. 2010;36(5):23341. doi:10.3109/00952990.2010.491884.

11. Shah KR, Eisen SA, Xian H, Potenza MN. Genetic studies of pathological gambling: a review of methodology and analyses of data from the Vietnam Era Twin Registry. J Gambl Stud. 2005;21(2):179-203. doi:10.1007/s10899-005-3031-x.

12. Lind PA, Zhu G, Montgomery GW, Madden PA, Heath AC, Martin $\mathrm{NG}$, et al. Genome-wide association study of a quantitative disordered gambling trait. Addict Biol. 2012;18:511-22. doi:10.1111/j. 1369-1600.2012.00463.x.

13. Slutske WS, Eisen S, True WR, Lyons MJ, Goldberg J, Tsuang M. Common genetic vulnerability for pathological gambling and alcohol dependence in men. Arch Gen Psychiatry. 2000;57(7):666-73. doi:10.1001/archpsyc.57.7.666.

14. Slutske WS, Ellingson JM, Richmond-Rakerd LS, Zhu G, Martin NG. Shared genetic vulnerability for disordered gambling and alcohol use disorder in men and women: Evidence from a national community-based Australian twin study. Twin Res Hum Genet. 2013;16(2):525-34. doi:10.1017/thg.2013.11.

15. Black DW, Moyer T, Schlosser S. Quality of life and family history in pathological gambling. J Nerv Ment Dis. 2003;191(2):124-6. doi:10.1097/00005053-200302000-00011.

$16 . \bullet$ Noël X, Brevers D, Bechara A. A neurocognitive approach to understanding the neurobiology of addiction. Curr Opin Neurobiol. 2013;23(4):632-8. doi:10.1016/j.conb.2013.01.018. This article provides a comprehensive review on neuroscience's understanding of addiction. The article incorporates gambling disorder within the review, and discusses three interconnected neural systems within the brain that are impacted during addiction and influence future behavior.

17. Potenza MN. Neurobiology of gambling behaviors. Curr Opin Neurobiol. 2013;23(4):660-7. doi:10.1016/j.conb.2013.03.004.

18. Hesselbrock VM, Hesselbrock MNA. Are there empirically supported and clinically useful subtypes of alcohol dependence? Addiction. 2006;101(S1):97-103.

19.• Blaszczynski A, Nower L. A pathways model of problem and pathological gambling. Addiction. 2002;97(5):487-99. doi:10. 1046/j.1360-0443.2002.00015.x. A theoretical paper on the developmental psychopathology pathways of gambling disorder. More recent articles have found strong support for the "Pathways Model.".

20. Denis C, Fatséas M, Auriacombe M. Analyses related to the development of DSM-5 criteria for substance use related disorders: 3 . An assessment of Pathological Gambling criteria. Drug Alcohol Depend. 2012;122(1-2):22-7. doi:10.1016/j.drugalcdep.2011.09. 006.

21. Lesieur HR, Rosenthal RJ. Pathological gambling: a review of the literature (prepared for the American Psychiatric Association Task Force on DSM-IV Committee on Disorders of Impulse Control not elsewhere classified). J Gambl Stud. 1991;7(1):5-39. doi:10.1007/ bf01019763.

22. Bartley CA, Bloch MH. Meta-analysis: pharmacological treatment of pathological gambling. Expert Rev Neurother. 2013;13(8):88794. doi:10.1586/14737175.2013.814938.

23.• Hodgins DC, Stea JN, Grant JE. Gambling disorders. Lancet. 2011;378(9806):1874-84. doi:10.1016/s0140-6736(10)62185-x. This review article provides a concise, yet comprehensive, review on gambling disorder and its treatment.
24. Cowlishaw S, Merkouris S, Chapman A, Radermacher H. Pathological and problem gambling in substance use treatment: a systematic review and meta-analysis. J Subst Abus Treat. 2013. doi:10.1016/j.jsat.2013.08.019.

25. Ibáñez A, Blanco C, Donahue E, Lesieur HR, Pérez de Castro I, Fernández-Piqueras J, et al. Psychiatric comorbidity in pathological gamblers seeking treatment. Am J Psychiatr. 2001;158(10):1733-5. doi:10.1176/appi.ajp.158.10.1733.

26. Abbott MW, Volberg RA, Rönnberg S. Comparing the New Zealand and Swedish National Surveys of gambling and problem gambling. J Gambl Stud. 2004;20(3):237-58. doi:10.1023/ B:JOGS.0000040278.08853.c0.

27. French MT, Maclean JC, Ettner SL. Drinkers and bettors: investigating the complementarity of alcohol consumption and problem gambling. Drug Alcohol Depend. 2008;96(1-2):155-64. doi:10. 1016/j.drugalcdep.2008.02.011.

28. Rash CJ, Weinstock J, Petry NM. Drinking patterns of pathological gamblers before, during, and after gambling treatment. Psychol Addict Behav. 2011;25(4):664-74. doi:10.1037/ a0025565.

29. Hodgins DC, el-Guebaly N. The influence of substance dependence and mood disorders on outcome from pathological gambling: fiveyear follow-up. J Gambl Stud. 2010;26(1):117-27.

30. Ledgerwood DM, Downey KK. Relationship between problem gambling and substance use in a methadone maintenance population. Addict Behav. 2002;27(4):483-91. doi:10.1016/s03064603(01)00187-3.

31. Cicchetti D, Rogosch FA. Equifinality and multifinality in developmental psychopathology. Dev Psychopathol. 1996;8(4):597600. doi: $10.1017 / \mathrm{s} 0954579400007318$.

32.• Nolen-Hoeksema S, Watkins ER. A heuristic for developing transdiagnostic models of psychopathology: explaining multifinality and divergent trajectories. Perspect Psychol Sci. 2011;6(6):589-609. doi:10.1177/1745691611419672. A theoretical article about transdiagnostic models of psychopathology and how underlying factors can lead to the development of different disorders. The discussion regarding the different levels of transdiagnostic factors is particularly useful in conceptualizing how these factors interact and play out over time.

33. McCormick J, Delfabbro P, Denson LA. Psychological vulnerability and problem gambling: an application of Durand Jacobs' general theory of addictions to electronic gaming machine playing in Australia. J Gambl Stud. 2012;28(4):665-90. doi:10.1007/ s10899-011-9281-x.

34.• el-Guebaly N, Mudry T, Zohar J, Tavares H, Potenza MN. Compulsive features in behavioural addictions: the case of pathological gambling. Addiction. 2012;107(10):1726-34. doi:10.1111/ j.1360-0443.2011.03546.x. A review article on gambling disorder and the overlap between the disorder and substance use disorders (SUD) and obessesive compulsive disorder (OCD). Greater overlap exists between gambing disorder and SUD than OCD. However, complusive features of gambling disorder in the context of withdrawal are discussed.

35. Walther B, Morgenstern M, Hanewinkel R. Co-occurrence of addictive behaviours: personality factors related to substance use, gambling and computer gaming. Eur Addict Res. 2012;18(4): 167-74. doi:10.1159/000335662.

36. Najavits LM, Smylie D, Johnson K, Lung J, Gallop RJ, Classen CC. Seeking safety therapy for pathological gambling and PTSD: a pilot outcome study. J Psychoactive Drugs. 2013;45(1):10-6. doi: 10.1080/02791072.2013.763557.

37. Álvarez-Moya EM, Ochoa C, Jiménez-Murcia S, Aymamí MN, Gómez-Peña M, Fernández-Aranda F, et al. Effect of executive functioning, decision-making and self-reported impulsivity on the treatment outcome of pathological gambling. J Psychiatry Neurosci. 2011;36(3):165-75. doi:10.1503/jpn.090095. 
38. Smith D, Harvey P, Battersby M, Pols R, Oakes J, Baigent M. Treatment outcomes and predictors of drop out for problem gamblers in south Australia: a cohort study. Aust N Z J Psychiatry. 2010;44(10):911-20. doi:10.3109/00048674.2010.493502.

39. Leblond J, Ladouceur R, Blaszczynski A. Which pathological gamblers will complete treatment? Br J Clin Psychol. 2003;42(2): 205-9. doi:10.1348/014466503321903607.

40. Korman L, Collins J, Littman-Sharp N, Skinner W, McMain S, Mercado V. Randomized control trial of an integrated therapy for comorbid anger and gambling. Psychother Res. 2008;18(4):454 65. doi:10.1080/10503300701858362.

41. Sanislow CA, Pine DS, Quinn KJ, Kozak MJ, Garvey MA, Heinssen RK, et al. Developing constructs for psychopathology research: research domain criteria. J Abnorm Psychol. 2010;119(4): 631-9. doi:10.1037/a0020909.

42. Narrow WE, Clarke DE, Kuramoto SJ, Kraemer HC, Kupfer DJ, Greiner L, et al. DSM-5 field trials in the United States and Canada, part III: development and reliability testing of a cross-cutting symptom assessment for DSM-5. Am J Psychiatry. 2013;170(1):71-82. doi:10.1176/appi.ajp.2012.12071000.

43. Strong DR, Kahler CW. Evaluation of the continuum of gambling problems using the DSM-IV. Addiction. 2007;102(5):713-21. doi: 10.1111/j.1360-0443.2007.01789.x.

44. Orford J, Wardle H, Griffiths M, Sproston K, Erens B. PGSI and DSM-IV in the 2007 British Gambling Prevalence Survey: reliability, item response, factor structure and inter-scale agreement. Int Gambl Stud. $2010 ; 10(1): 31-44$. doi:10.1080/ 14459790903567132.

45. Blanco C, Hasin DS, Petry N, Stinson FS, Grant BF. Sex differences in subclinical and DSM-IV pathological gambling: results from the National Epidemiologic Survey on Alcohol and Related Conditions. Psychol Med. 2006;36(7):943-53. doi:10.1017/ s0033291706007410.

46. Toce-Gerstein M, Gerstein DR, Volberg RA. A hierarchy of gambling disorders in the community. Addiction. 2003;98(12):166172. doi:10.1111/j.1360-0443.2003.00545.x.

47. Weinstock J, Rash C, Burton S, Moran S, Biller W, O'Neil K, et al. Examination of proposed DSM-5 changes to pathological gambling in a helpline sample. J Clin Psychol. 2013;69(12):1305-14.

48. Zimmerman M, Chelminski I, Young D. A psychometric evaluation of the DSM-IV pathological gambling diagnostic criteria. J Gambl Stud. 2006;22(3):329-37. doi:10.1007/s10899-006-9020-x.

49. Stinchfield R. Reliability, validity, and classification accuracy of a measure of DSM-IV diagnostic criteria for pathological gambling. Am J Psychiatry. 2003;160(1):180-2. doi:10.1176/appi.ajp.160.1.180.

50. Jiménez-Murcia S, Stinchfield R, Álvarez-Moya E, Jaurrieta N, Bueno B, Granero R, et al. Reliability, validity, and classification accuracy of a Spanish translation of a measure of DSM-IV diagnostic criteria for pathological gambling. J Gambl Stud. 2009;25(1): 93-104. doi:10.1007/s10899-008-9104-X.

51. Stinchfield R, Govoni R, Firsch GR. DSM-IV diagnostic criteria for pathological gambling: reliability, validity, and classification accuracy. Am J Addict. 2005;14(1):73-82. doi:10.1080/ 10550490590899871.

52. Scherrer JF, Xian H, Shah KR, Volherg R, Slutske W, Eisen SA. Effect of genes, environment, and lifetime co-occurring disorders on health-related quality of life in problem and pathological gamblers. Arch Gen Psychiatry. 2005;62(6):677-83. doi:10.1001/ archpsyc.62.6.677.

53. Rennert L, Denis C, Peer K, Lynch KG, Gelernter J, Kranzler HR. DSM-5 gambling disorder: prevalence and characteristics in a substance use disorder sample. Exp Clin Psychopharmacol. 2014;22(1):50-6. doi:10.1037/a0034518.

54. Grall-Bronnec M, Wainstein L, Feuillet F, Bouju G, Rocher B, Vénisse J-L, et al. Clinical profiles as a function of level and type of impulsivity in a sample group of at-risk and pathological gamblers seeking treatment. J Gambl Stud. 2012;28(2):239-52. doi:10. 1007/s10899-011-9258-9.

55. Larimer ME, Neighbors C, Lostutter TW, Whiteside U, Cronce JM, Kaysen D, et al. Brief motivational feedback and cognitive behavioral interventions for prevention of disordered gambling: a randomized clinical trial. Addiction. 2012;107(6):1148-58. doi:10. 1111/j.1360-0443.2011.03776.x.

56. Andrews G, Sunderland M, Kemp A. Consistency of diagnostic thresholds in DSM-V. Aust N Z J Psychiatry. 2010;44(4):309-13. doi:10.3109/00048670903487241.

57. Hodgins DC, Currie SR, Currie G, Fick GH. Randomized trial of brief motivational treatments for pathological gamblers: more is not necessarily better. J Consult Clin Psychol. 2009;77(5):950-60. doi: 10.1037/a0016318.

58. Olsen CM. Natural rewards, neuroplasticity, and non-drug addictions. Neuropharmacology. 2011;61(7):1109-22. doi:10.1016/j. neuropharm.2011.03.010.

59. Karim R, Chaudhri P. Behavioral addictions: an overview. J Psychoactive Drugs. 2012;44(1):5-17. doi:10.1080/02791072. 2012.662859.

60. Petry NM. Should the scope of addictive behaviors be broadened to include pathological gambling? Addiction. 2006;101 Suppl 1:15260.

61. Potenza MN. Should addictive disorders include non-substancerelated conditions? Addiction. 2006;101 Suppl 1:142-51. doi:10. 1111/j.1360-0443.2006.01591.x.

62. Petry NM, Rehbein F, Gentile DA, Lemmens JS, Rumpf H-J, Mößle T et al. An international consensus for assessing internet gaming disorder using the new DSM-5 approach. Addiction. Epub 2014 Jan 23. doi: 10.1111/add.12457.

63. LaPlante DA, Nelson SE, LaBrie RA, Shaffer HJ. Stability and progression of disordered gambling: lessons from longitudinal studies. Can J Psychiatry. 2008;53(1):52-60.

64. Slutske WS. Natural recovery and treatment-seeking in pathological gambling: results of two U.S. national surveys. Am J Psychiatry. 2006;163(2):297-302.

65. Slutske WS, Blaszczynski A, Martin NG. Sex differences in the rates of recovery, treatment-seeking, and natural recovery in pathological gambling: results from an Australian community-based twin survey. Twin Res Hum Genet. 2009;12(5):425-32. doi:10. 1375/twin.12.5.425.

66. Arria AM, McLellan AT. Evolution of concept, but not action, in addiction treatment. Subst Use Misuse. 2012;47(8-9):1041-8. doi: 10.3109/10826084.2012.663273

67. Clark L, Studer B, Bruss J, Tranel D, Bechara A. Damage to insula abolishes cognitive distortions during simulated gambling. Proc Natl Acad Sci U S A. 2014;111(16):6098-103. doi:10.1073/pnas. 1322295111.

68.• Naqvi NH, Gaznick N, Tranel D, Bechara A. The insula: a critical neural substrate for craving and drug seeking under conflict and risk. Ann N Y Acad Sci. 2014;1316(1):53-70. doi:10.1111/nyas. 12415. A detailed overview of the insula region of the brain and its relationship to addiction. The authors provide a conceptual framework for three different ways in which the insula plays a role in maintaining addictive behaviors. Prominent in this review is how learning and negative reinforcement maintain the maladaptive addictive behavior via the insula.

69. Delfabbro P, Lahn J, Grabosky P. It's not what you know, but wow you use it: statistical knowledge and adolescent problem gambling. J Gambl Stud. 2006;22(2):179-93. doi:10.1007/ s10899-006-9009-5.

70. de Lisle SM, Dowling NA, Allen JS. Mindfulness and problem gambling: a review of the literature. J Gambl Stud. 2012;28(4):71939. doi:10.1007/s10899-011-9284-7. 